\title{
Revisiting Brown and Levinson's Politeness Theory: A Middle-Eastern Perspective
}

\author{
Tahani Saleh Alabdali \\ College of Languages and Translation- English Department- IMISIU Riyadh- Saudi Arabia \\ s_tahani@hotmail.com
}

\begin{abstract}
This article attempts to examine the theory of politeness proposed by Brown and Levinson in 1978. It presents its strengths and weaknesses from the point of view of many experienced linguists. Furthermore, the author contributes with her own observations and research results in relation to the theory and its applicability in Middle Eastern, particularly Arabic speaking communities. This article tackles the theory from a Middle Eastern perspective, when so far it has been mainly discussed in Western or Far Eastern cultures. The findings suggest that certain factors need to be added to the formula which Brown and Levinson (1978) have put forward as a means to calculate the weightiness of face-threatening acts. Such factors relate to the specific religious, environmental, and gestural aspects of different speech communities. Nevertheless, the theory proved to be applicable to a wide range of Western as well as Eastern cultures.
\end{abstract}

Keywords: Pragmatics, Brown and Levinson, politeness, critical review, Middle East, Arabic culture.

The politeness theory proposed by Brown and Levinson (1978) is one of the most comprehensive and widely tested theories in the field of pragmatic politeness. It covered many areas and proved to be highly applicable in most cultures. However, the theory is assumingly Westernbiased, and lacks the inclusion of elements which are more related to many Middle-Eastern cultures and speech communities (Bharuthram, 2003; Nwoye, 1992; Shum, 2008). That does not mean, in any way, that the theory is not suitable for such cultures. However, expanding the theory to include some effective elements in the presentation and perception of politeness in these cultures would probably contribute to the universality of the theory. Therefore, this paper attempts to fill the gap existing in the theory in relation to Middle-Eastern cultures.

\section{Summary of the theory}

The theory reviewed in this article was first developed in 1978 by Penelope Brown and Steven Levinson. It was published as an article in the journal 'Questions and politeness: Strategies in social interaction' (Brown \& Levinson, 1978). Later, it was issued as an independent book in 1987 (Brown \& Levinson, 1987). This review is based on the latest printed edition, which is dated 2011.

Brown and Levinson developed their theory in an attempt to identify the universal social principles and their effect on reshaping grammar. They intended to do that through understanding the reasoning behind speakers' and hearers' choices in their everyday interaction. They primarily relied on the concepts of 'face' and 'rationality' in their account of speakers' linguistic behavior, claiming universality for these two concepts. They assumed that one of the most common reasons for flouting one or more of Grice's maxims (1975) is to be polite. This assumption, I believe, is logical especially when considering situations where abiding by these maxims results in impolite utterances. 
The theory they came up with accounted for cultural similarities, and even differences, in polite linguistic usage. They based their model on the analysis of the speech of a Model Person (MP), an assumed fluent speaker of a natural language who is endowed with rationality and face; both positive and negative faces. The speaker

(S) and the addressee or hearer $(\mathrm{H})$ are both considered MPs. B\&L (1987) analyzed speech in light of speech act theory, i.e. they treated utterances as acts which are used to convey certain meanings and carry out certain functions. They also assumed that certain acts are intrinsically face threatening either to the face of S or H. Such acts are termed face-threatening acts FTAs.

In normal situations, interactants employ different sorts of strategies to avoid the bad effect of FTAs either to H's face or to S's face. They are usually motivated by a number of socio-cultural factors for using specific strategies in particular situations in what B\&L believe to be a universal fashion. B\&L (1987) proposed five superstrategies, which are considered the general methods $S$ would choose from in a particular interaction.

In their theory, B\&L (1987) explained the factors influencing people's choices of the strategy to be used. They argued that speakers in different societies and cultures tend to use certain strategies in similar circumstances because such strategies would afford desired payoffs or advantages. They assumed that the nature of the payoffs of different strategies as well as the relevant social and cultural circumstances of the context, i.e. the interactants' social distance (D), relative power (P), and the ranking of the imposition of an act in a particular culture $(\mathrm{R})$, are the most influential factors in people's decision of which strategy to use. B\&L believed that in all cultures, S's assessment of the seriousness of an FTA involves these three contextual factors, D, P, and R, which are contextdependent in the sense that their value changes according to the situation even if $\mathrm{S}$ and $\mathrm{H}$ remain constant.

Thus, the computation of the weightiness of an FTA is both culture- and contextdependent. And as the weightiness of an act increases, a rational agent would tend to use the highernumbered strategies. For example, a rational speaker would take the least risk to minimize facethreats by using one of the higher-numbered strategies when talking to a stranger (high $\mathrm{D}$ value), a dominant member of the community (high $\mathrm{P}$ value), or when making a serious imposition (high $\mathrm{R}$ value).

The theory has been reviewed by many linguists (Eelen, 2001; Fraser, 1990; Frey, 1999; Kasper, 1990; Leech, 2005; Mills, 2003). One of the most-commonly criticized points is the claim of universality, which was considered ambitious since the original theorists, i.e. B\&L, lacked extensive work to prove such a conclusion. However, despite their criticism of the theory in many aspects, some are shared among a few of them, these critics agreed that B\&L's theory of politeness (1987) is one of the most comprehensive, highly influential theories in the field. Some of their critical points will be discussed hereafter alongside the author's own.

\section{Review of the theory}

Although one of the most apparent strengths of this theory is its attempt to come up with a universal theory of politeness, yet it was the area where it was criticized the most (Al-Duleimi, Rashid, Abdullah, 2016; Al-Hindawi, Alkhazaali, 2016). In their attempt, Brown and Levinson (1978) followed a Generative Linguistic approach, assuming that the internal linguistic and social capacities of humans from different cultures and linguistic backgrounds are the same. Thus, it is assumed that people from different cultures tend to behave in similar ways under the same circumstances (Antovic, 2007). This assumption leads us to believe that it is possible to overcome interactive obstacles arising from varying backgrounds. However, limiting the affecting variables to the contextual P, D, and R is a bit over-simplistic, an opinion I share with both Fraser (1990) and Kasper (1990). Factors relating to the idiosyncrasy of individual interactans need to be taken into consideration in any politeness theory. For example, the speaker's social class, level of education, 
urbanity, age and gender are all factors affecting the way individuals speak. These factors may affect not only the use of polite expressions, but also the definition of what is polite and what is not in a given culture or speech community.

In addition to strongly believing in the necessity of including the factor of age in any politeness theory as a factor influencing the frequency and type of use of polite expressions, I believe that age contributes more to the definition of what constitutes a polite expression more than to when to be polite. It sometimes causes conversational breakdowns among people of different generations within the same speech community. So, what is considered polite or impolite most probably differs from one generation to another.

Moreover, B\&L (1987) assumed rationality for their Model Person. Any rational speaker would take into consideration the status of the addressee, not only in relation to their $\mathrm{P}, \mathrm{D}$, and $\mathrm{R}$, but in relation to the same idiosyncratic factors mentioned earlier, little to say about the effect of bystanders and their relationship with both $\mathrm{S}$ and $\mathrm{H}$. Some of the above factors, however, might be effective in one culture but not the other. For example, the gender of the addressee was found effective in many Middle Eastern communities but not in Western ones (Al-Qahtani, 2009; Tawalbeh,\& Al-Oqaily, 2012). Moreover, some of these factors seem to have an overriding effect over others. If a young doctor, for instance, was treating an old patient, who would be more polite to the other? Ide (1982), for example, claimed that the patient would be more polite towards the doctor which is a reflection of how $\mathrm{P}$ has a strong effect on the verbal interaction of participants in the Japanese culture.

I also believe that there are other factors which need to be taken into consideration in any politeness theory. Environmental factors, such as political revolutions, were found to be influential in redefining polite expressions in some middle eastern societies (Omar, Ilyas, and Kassem, 2018). Moreover, Religious beliefs proofed indispensable in the representation of politeness expressions of many speakers in the Muslim world (Akbari, 2002; Al-Adaileh, 2007; Al-Khatib, 2006; Hamed, 2014). Such expressions were classified in different ways by different researchers; as in-group identity markers (Al-Qahtani, 2009), as hedges (Nureddeen, 2008), or as gifts to H (Akbari, 2002; Alabdali, 2015). Religious expressions used for politeness purposes can be found in other cultures as well. Therefore, their use should be included as an independent output strategy.

Some other linguistic and extra-linguistic factors need to be taken into consideration in any universal theory of politeness. Facial expressions, body language, intonation and its varying representations in a given speech community, the medium of the interaction, and the discourse type are elements that may influence the production and interpretation of polite expressions.

One of the interesting assumptions made by B\&L (1987) is that an utterance is rated as more or less polite than other similar utterances conveying the same act based not only on the actual expressions produced by $\mathrm{S}$ but also on the internal organization of the utterance. Thus, if we have two utterances produced for the same purpose in the same circumstances with the same wording, we still could judge one of them as being more polite than the other if the word order and topicalization of the two utterances are different. When $\mathrm{S}$ pays more attention to the face needs of $\mathrm{H}$ by topicalizing the polite expression, their utterance is considered more polite than an utterance where the main act is topicalized. This point highlights the significance of the psychological factor in the production and perception of the act, a factor which importance was emphasized by many politeness critics (Eelen, 2001; Leech, 2005).

One of the drawbacks of the theory under investigation is lacking precise definitions of the sociocultural factors. B\&L's definition of the $\mathrm{P}$ variable, for example, was much clearer than their definition of the $\mathrm{D}$ and especially the $\mathrm{R}$ variables. The $\mathrm{D}$ variable, for example, did not account for cases where the interactants are not total strangers yet not acquaintances, such as the case when you know the look of someone from work or school but you do not even know their names. The $\mathrm{R}$ variable, which refers to the rank of an act in a specific speech community, was left solely to the 
understanding and evaluation of the reader or the researcher applying the model. It definitely needed to be explained more thoroughly in terms of the parameters contributing to its evaluation.

B\&L (1987) also explained how speakers are capable of manipulating the social roles of the interactants, especially in the mind of a third party, by their marked use of polite expression. So, they assumed that when $\mathrm{S}$ gives an order to $\mathrm{H}$, it is assumed that $\mathrm{S}$ has a higher $\mathrm{P}$ status than $\mathrm{H}$, even if that is not true. This shows how polite expressions can influence the future relationships of the interactants. What B\&L dismissed, however, was the influence of the interactants' history and future relationship on the politeness level of their present interaction. A speaker would tend to speak more politely than expected with someone of less power if they think that $\mathrm{H}$ would have different $\mathrm{P}$ status in the future (Alabdali, 2015).

In their discussion of saving face, B\&L focused on H's face. They claimed, that S's intention is mainly to save H's face. They mentioned that sometimes strategies are utilized for the saving of S's face, yet in the discussion of their model, they mainly highlighted how these strategies are used to safe H's face. However, I believe that the main purpose of speakers manipulation of their speech is to serve their own needs; their need to be understood, to be attended to, to be served, and to be respected and not humiliated or rejected. In other words, by being polite, $\mathrm{S}$ is mainly saving their own face.

In the discussion regarding the effort put into a polite expression, $B \& L$ assumed that the more effort $S$ puts into an expression, by combining two strategies of the same type in one utterance for instance, the more polite the expression is rated. However, I believe that putting more effort than expected in an utterance gives the same result as choosing a higher risk strategy for a small FTA. In both cases, $\mathrm{H}$ might deduce that the FTA is riskier, or more face threatening, than it actually is. Therefore, I suggest that the effort put into the formulation of a polite utterance be treated as an independent strategy to redress $\mathrm{H}$ 's and/or S's face just like negative, and positive politeness strategies.

Keeping in mind the social factor, which refers to the influence the society has on the polite choices of its members (Leech, 2005), and the rationality of the speakers, I believe that producing polite expressions is the expected norm in normal circumstances in any given speech community. Therefore, the scope of politeness should include, in addition to defining specific politeness repertoires in different speech communities, the study of intrinsically impolite expressions with surface polite utterances. This might be understood as referring to FTAs as used in B\&L's theory. However, I believe that in many situations $\mathrm{S}$ uses a polite expression with an impolite intention to serve personal purposes, like being sarcastic or sounding clever. Therefore, I second Kasper (1990) in criticizing the theory for assuming that human interaction is based on conflict-avoidance which is rather a pessimistic view of human relations and human interactions.

One of the points that received criticism was the ranking of the superstrategies. B\&L assumed that they are ranked as follows, starting with the least polite: bold-on-record, positive politeness, negative politeness, off-record, and finally do not do the act. Blum-Kulka (1987) conducted a study on the Israeli culture that contradicted this hierarchal order. One of the findings of his study was that in some cases direct requests and conventionally indirect requests are considered more polite than indirect requests which correspond to the off-record superstrategy.

Fraser (1990) and Kasper (1990) criticized B\&L's model for its oversimplicity. I believe, however, that over-simplicity is a pre-requisite of the universality trait. A universal theory would be over complicated if it analyzes all the details of the investigated phenomenon. In order to allow for the inclusion of all linguistic verities and/or cultures, a theory (or a model) better attempts to explain the main factors contributing to the phenomenon, leaving sufficient margins for cultural and linguistic differences.

Finally, I believe that B\&L's model might be insufficient in explaining how the analysis process can be carried out. For example, it does not discuss how factors like the elements contributing to the background information of the interactants ( $\mathrm{S}$ 's and H's age, gender, class, 
education, their potential future relations etc..) in addition to the analyst's own linguistic and cultural background can contribute to the analysis of conversations. Therefore, a modified version of the model needs to take into consideration not only the actual words used in the interaction, i.e. the utterance, but all the background factors of the interactants in particular and the setting in general which affect, and might be affected in the future by, the production of the utterance.

In conclusion, I believe that the politeness model proposed by B\&L (1987) was adequately comprehensive and thoroughly exemplified to account for the politeness phenomenon in many cultures. The model was applicable, in most part, even in studies that claimed that the model was Western-biased and exclusive of non-Western cultures (Bharuthram, 2003; Nwoye, 1992; Shum, 2008). The actual over-generalized aspects of the model, I believe, are the proposed relation between indirectness and politeness (Blum-Kulka, 1987), and the hierarchy of politeness super-strategies. Therefore, the model needs to be reconsidered, especially in these two areas, with the potential for including more output strategies, and a consideration of other extra-linguistic factors in the judgement of politeness in utterances.

\section{Recommendations:}

The following points need to be considered in a revisited version of the theory:

[1] The assumed direct relation between the level of indirectness and the level of politeness should no longer be finalized.

[2] More output strategies with cultural and religious connotations need to be added to include speech communities that are more attached to traditions and religious beliefs.

[3] Some effective elements need to be added to the equation of politeness. For example, the speaker's assumption of his right in performing the act, the presence of bystanders, and the contribution of extralinguistic factors, like body language and facial expressions, to the overall politeness level of the interaction.

\section{References}

[1] Akbari, Z., The realization of politeness principles in Persian, Karen's Linguistic Issues, 2, 1-22(2002), doi:10.1.1.507.4135

[2] Alabdali. T, Strategies of Politeness in Requests as Used by Najdi Female Speakers (doctoral dissertation). King Saud University, Saudi Arabia, (2015)

[3] Al-Adaileh. B., The speech act pf apology: A linguistic exploration of politeness orientation in British and Jordanian culture (doctoral dissertation). The University of Leeds, England, (2007)

[4] Al-Duleimi. H., Rashi. S. \& Abdullah. A., A Critical review of prominent theories of politeness, Advances in Language and Literary Studies, 7(6)(2016)

[5] Al-Hindawi. F \& ALkhazaali. M., A critique of politeness theories, Theory and Practice in Language Studies, 6(8)(2016), 1537-1545, https://doi.org/10.17507/tpls.0608.03

[6] Al-Khatib. M. A., The pragmatics of invitation making and acceptance in Jordanian society, Journal of Language and Linguistics, 5(2)(2006), 272-294.

[7] Al-Qahtani. H., Female use of politeness strategies in the speech act of offering: A contrastive study between spoken Saudi Arabic and spoken British English (Master's thesis), King Saud University, Saudi Arabia, (2009)

[8] Antovic, Mihailo, Half a century of generative linguistics_ What has the paradigm given to social sciences? Linguistics and Literature, 5(1)(2007), 31-46. 
[9] Bharuthram. S., Politeness phenomena in the Hindu sector of the South African Indian English speaking community, Journal of Pragmatics, 35(10-11)(2003),1523-1544, https://doi.org/10.1016/s03782166(03)00047-x

[10] Blum-Kulka. S., Indirectness and politeness in requests: Same or different?, Journal of Pragmatics, 11(2) (1987), 131-146, https://doi.org/10.1016/0378-2166(87)90192-5

[11] Brown. P., \& Levinson. S., Universals in Language usage: Politeness phenomena. In E. N. Goody (Ed.), Questions and politeness: Strategies in social interaction, 8(1978), 56-289. (Cambridge: Cambridge University Press)

[12] Brown. P., \& Levinson. S. C., Politeness: Some universals in language usage, Cambridge University Press, Cambridge, (1987)

[13] Eelen. G., A critique of politeness theories, St. Jerome Publishing, Manchester, (2001)

[14] Fraser. B., Perspectives on politeness, Journal of pragmatics, 14(1990), 219-236, https://doi.org/10.1016/0378-2166(90)90081-N

[15] Frey. H., Politeness: Theoretical approaches and language practice- Brown and Levinson reviewed, Druck and Bindung, Germany, (1999)

[16] Grice. H. P., Logic and conversation. (In P. Cole \& J. L. Morgan, Syntax and Semantics (Eds.): Speech Acts 3, (pp. 41-58). Academic Press, New York, (1975)

[17] Hamed. A. M., A contrastive study of politeness and impoliteness strategies in British and Arab sports media discourse (Master's thesis), Fayoum University, Egypt, (2014)

[18] Ide. S., Japanese sociolinguistics: Politeness and Women's language. Lingua, 57(2-4)(1982), 357-385, https://doi.org/10.1016/0024-3841(82)90009-2

[19] Kasper. G., Linguistic politeness: Current research issues, Journal of Pragmatics, 14(2)(1990), 193-218, https://doi.org/10.1016/0378-2166(90)90080-W

[20] Leech. G., Politeness: Is there an East-West divide?, Journal of Foreign Languages, 6(2005), 1-30, DOI:1004-5139

[21] Mills. S., Gender and politeness, Cambridge University Press, Cambridge, (2003)

[22] Nureddeen. F. A., Cross cultural pragmatics: Apology strategies in Sudanese Arabic, Journal of Pragmatics, 40(2)(2008), 279-306, https://doi.org/10.1016/j.pragma.2007.11.001

[23] Nwoye. O. G., Linguistic politeness and socio-cultural variations of the notion of face, Journal of Pragmatics, 18(4)(1992), 309-328, https://doi.org/10.1016/0378-2166(92)90092-p

[24] Omar. A., Ilyas. M. \& Kassem. M., Linguistic Politeness and Media Education: A Lingua-Pragmatic Study of Changing trends in 'Forms of Address' in Egyptian Media Talk Shows, Journal of Social Studies Education Research. 9(2)(2018), 349-365

[25] Shum. A. O. N., Being Positively polite: Women making requests in Hong Kong workplaces, LCOM, 2(2008), 27-43

[26] Tawalbeh. A., \& Al-Oqaily. E., In-directness and politeness in American English and Saudi Arabic requests: A cross-cultural comparison, Asian Social Science, 8(10)(2012), 85-98, https://doi.org/10.5539/ass.v8n10p85 